\title{
Male Involvement in Family Planning: Challenges and Way Forward
}

\author{
Ademola Adelekan, ${ }^{1}$ Philomena Omoregie, ${ }^{2}$ and Elizabeth Edoni ${ }^{3}$ \\ ${ }^{1}$ Department of Research and Reproductive Health, Public Health Promotion Alliance, Osogbo 3166, Nigeria \\ ${ }^{2}$ Department of Health Promotion and Education, Faculty of Public Health, University of Ibadan, Ibadan 2000005, Nigeria \\ ${ }^{3}$ Department of Community Health Nursing, Niger-Delta University, Wilberforce Island 569108, Nigeria
}

Correspondence should be addressed to Ademola Adelekan; kingadelekan@gmail.com

Received 3 January 2014; Revised 1 April 2014; Accepted 3 May 2014; Published 26 May 2014

Academic Editor: Kathryn Kost

Copyright (C) 2014 Ademola Adelekan et al. This is an open access article distributed under the Creative Commons Attribution License, which permits unrestricted use, distribution, and reproduction in any medium, provided the original work is properly cited.

Public health officials have advocated the involvement of men as a strategy for addressing the dismal performance of family planning (FP) programmes. This study was therefore designed to explore the challenges and determine way forward to male involvement in FP in Olorunda Local Government Area, Osogbo, Nigeria. This cross-sectional study involved the use of a four-stage sampling technique to select 500 married men and interviewed them using semistructured questionnaire. In addition, four focus group discussions (FGDs) were also conducted. Mean age of respondents was $28.5 \pm 10.3$ years. Some (37.9\%) of the respondents' spouse had ever used FP and out of which $19.0 \%$ were currently using FP. Only $4.8 \%$ of the respondents had ever been involved in FP. Identified barriers to male involvement included the perception that FP is woman's activity and was not their custom to participate in FP programme. More than half of the FGD discussants were of the view that men should provide their wives with transport fare and other resources they may need for FP. The majority of the respondents had never been involved in family planning with their wives. Community sensitization programmes aimed at improving male involvement in FP should be provided by government and nongovernmental agencies.

\section{Background}

In Nigeria, the 2008 NDHS found that only $10 \%$ of married women of reproductive age use contraceptives. This is lower than the current Sub-Saharan Africa average of 17\%. Further analysis of the total contraceptive prevalence rate (CPR) indicates wide state variations, ranging from 0.3 in Jigawa to 41.6 in Lagos state, as well as zonal variations ranging from 2.7 in the North West to 28.5 in the South West [1]. Nigeria's fertility rate has remained high: from 6.0 children per woman in 1990 it recorded only a minimal drop to 5.7 in 2008. Similarly, modern contraceptive prevalence has been around $10 \%$ (11\% in 2008) for the past decade [1]. The majority of married women in Nigeria are not currently using contraceptives and have no intention of doing so in the near future [2]. Although contraceptive methods and services are frequently geared toward women, men are often the primary decision makers on family size and their partner's use of FP methods [3-5]. In addition, spousal disagreement can serve as deterrent because women might fear initiating a difficult conversation about FP [6].

The use of any method of FP by women is often influenced by their husbands [7]. Men have rarely been involved in either receiving or providing information on sexuality, reproductive health, or birth spacing. They have also been ignored or excluded in one way or the other from participating in many FP programmes as FP is viewed as a woman's affair [8]. Traditionally, men are the heads of households and decision makers in all issues in their respective households. Men decide on FP and the number of children as well as how to use what is produced by the family. Also, findings have shown that since men were the decision makers, they were expected to initiate discussions on FP and the number of the children the couple want to have [8]. Men were perceived as the sole providers for their family needs. Women were not considered decision makers, but implementers of what had been decided 
by men, without questioning men's decisions [8]. The high level of awareness about contraception but very low level of use has been established in studies in Nigeria $[9,10]$. There are several obstacles to contraceptive use in Nigeria. Studies in Nigeria and elsewhere in sub-Saharan Africa have shown that major obstacles to the adoption of modern contraceptive behaviour include myths and misinformation or rumours and unconfirmed information passed within social networks [11-13]. Other reasons for this lack of FP use include fear of complications, lack of understanding of methods, and fear of opposition from the husband [9]. Nadia et al. [14] also identified evidence of fear of FP side effects among females and males from India, Nepal, and Nigeria.

Since the 1994 International Conference on Population and Development (ICPD), interest in men's involvement in reproductive health has increased. Evidence indicates that male involvement can lead to contraceptive uptake through the pathway of increased spousal communication $[15,16]$. However, FP programmes have traditionally focused on women as the primary beneficiaries and men have been considered as the silent partners of the services [17]. This study therefore is designed to determine the challenges and way forward to male involvement in FP in Olorunda Local Government Area (LGA), Osogbo, Nigeria.

\section{Methods}

2.1. Study Design. A cross-sectional descriptive study design was used for documenting the challenges and way forward to male involvement in FP in Olorunda Local Government Area, Osogbo, Nigeria.

2.2. Study Area. The study site for this study is Olorunda Local Government Area. The Local Government is one of the two LGAs in Osogbo, Osun State, Nigeria. The state has a stagnant total fertility rate of 5.7 in 2003 and 2008 [1]. The Local Government has its headquarter in Igbona and has an area of $97 \mathrm{~km}^{2}$ with a population of 131,761 at the latest 2006 census. The inhabitants are mainly Yoruba speaking, and majorly small-scale traders; $53.4 \%$ are Christian, $46.0 \%$ Muslim, and $0.5 \%$ Traditionalist [1]. Osogbo is the venue of the annual Osun-Osogbo festival along the River Osun. The festival is centered around the sacred grove of the river goddess Osun, which is a UNESCO World Heritage Site.

2.3. Study Population. The study population consisted of married men in Olorunda Local Government Area, Osun State. Married men with at least one child and within the age range of 18-50 years participated in the study.

2.4. Sample Size Determination. The sample size for the study was calculated using Lwanga and Lemeshow (1991) formula for sample size determination in health studies:

$$
n=\frac{z^{2} p q}{d^{2}}
$$

where $n=$ sample size; $z=$ the standard normal deviation which corresponds to the 95\% confidence level (1.96); $p=$ estimate of key proportion (20.69\% or 0.2069$)$. This prevalence is derived from a similar study [18]; $q=1-p(1-$ $0.2069=0.7931) ; d=$ degree of accuracy desired (0.05). Consider

$$
n=\frac{1.96^{2} \times 0.2069 \times 0.7931}{0.05^{2}}=252.1509 .
$$

The calculated sample size was increased to 500 so as to make provision for nonresponse and promote generalization of findings.

2.5. Sampling Procedure. For the qualitative study, one FGD each was conducted in all the 4 out of 10 randomly selected wards and the number of participants in each FGD was eight. Two each were conducted among those between the ages of 35-50 and 51-65 years. A total of thirty-two participants participated in these FGDs and were conducted with leaders of selected communities in all the four wards. The selection of FGD discussants was done using a nonprobability sampling technique involving purposive sampling. This implies that the FGD discussants were selected because of their position as leaders in their community. For the quantitative study, a total of five hundred consenting respondents were used and the following four-stage sampling technique was adopted in selecting the respondents.

Stage 1. The ten wards in the selected LGA were stratified into rural and urban wards.

Stage 2. Four out of ten wards in Olorunda were randomly selected for this study (two each in rural and urban strata).

Stage 3. Three communities each were conveniently selected from each ward.

Stage 4. At least one respondent was then chosen from every household until the required respondents were gotten.

2.6. Method for Data Collection. Both quantitative and qualitative (focus group discussion) methods were used for data collection. A focus group discussion guide which was developed by the researchers was used to collect information used in modifying the questions asked in the quantitative (questionnaire) data collection tool. There were eight major questions in the FGD guide that was used for the discussion and these questions focused on the married men's knowledge, perceptions, involvement, practice, barriers, and facilitating factors for male involvement in FP. The discussions were conducted in a suitable environment such as the community town hall and community leaders' compound. An interviewer-administered questionnaire was also used to obtain the necessary information from the respondents. The questionnaire was developed by the researchers based on the literature review and the information obtained from FGD together with input from health promotion specialists in the Faculty of Public Health, University of Ibadan. The questionnaire consisted of both open and close-ended questions and was administered by the research assistants. 
2.7. Data Collection Process. An FGD guide and semistructure questionnaire were developed and pretested among married men in Osogbo LGA. This LGA is also in Osun State and shares similar characteristics with the study area. Before pretesting, the research team discussed the two instruments to make sure that all involved in data collection understood and were acquainted with the instruments. The instruments were revised based on the issues identified by the team. The improved versions of the instruments were used for pretesting exercise. Both pretesting and actual data collection were conducted in local language commonly spoken in the area (Yoruba). Four (male $=3$, female $=1$ ) trained research assistants who have Master of Public Health Students at the University of Ibadan, Nigeria, were recruited and assisted the researchers in collecting data for the study. Focus group discussions were conducted jointly with research assistants and one of the investigators moderated all the discussions while research assistants did the note taking to complement the audio recording by the moderator. The moderator controlled the sessions to make sure that everyone including the shy people participated in the discussions to avoid missing the distinctive perceptions of less talkative respondents. During the FGD sessions, probing questions were posed to seek clarification on issues and to encourage participants to give more insights in their responses. Efforts were made to give respondents sufficient discussion time on key issues. The discussions were conducted in a quiet space to avoid noise interference and interruptions and each session lasted about 40-69 minutes. The discussions were audio-taped with the consent of the participants. For the quantitative study, a total of five hundred copies of questionnaires developed in Yoruba were administered among married men in the study area. Written consent of all the respondents was obtained and the objectives of the study were explained to them.

2.8. Data Management, Analysis, and Presentation. The completed copies of the questionnaire were serially numbered for control and recall purposes. Data collected was checked for completeness and accuracy on a daily basis. The quantitative data collected was collated and screened for completeness; knowledge and perception sections were scored and entered into computer. The Statistical Package for Social Science (SPSS) version 15 was used for the analysis of the data.

A 14-point knowledge scale was used to measure the respondents' knowledge of FP. A correct knowledge attracted a score of 1 point while a wrong knowledge was zero. A score of $\leq 6$ points was considered poor while scores of 7-10 and 11-14 points were considered fair and good knowledge, respectively. Perceptions of FP were determined using a 10point perception scale. For each question, positive perception attracted a score of 2 points; negative perception was zero while the score for undecided was 1 point. Scores of $\leq 5$ and $\geq 6$ points were considered negative and positive perceptions, respectively. Descriptive statistics and Chi-square were used. Frequencies were generated and variable was cross-tabulated. For the qualitative data, tapes were transcribed verbatim in Yoruba by the note takers and were subsequently translated into English by experts from the Department of Linguistics,
University of Ibadan, Nigeria. Spot checks of transcripts and translations were regularly conducted to ensure completeness of the transcription and accuracy of translation. The data were transcribed, sorted, categorized, and analyzed thematically. To check the internal consistency and reliability, data from the quantitative part was used to triangulate with the qualitative results.

2.9. Ethical Considerations. Approval for the study was sought from the Osun State Ministry of Health. Verbal information was provided to the respondents to make informed choices on whether to participate in the study or not. No incentives were provided to the respondents as a way of motivating them to participate in the study. All the respondents agreed to participate in the study and signed a consent form.

2.10. Limitation of the Study. The study focused on knowledge, perceptions, practice, involvement, and barriers to FP which are personal and sensitive. Some respondents were not willing to give all the information required by the researchers because of the fear of being penalized. Efforts were however made to reduce this problem by assuring them of the confidentiality of all information provided. It is assumed therefore that all responses were made in honesty.

\section{Results and Discussion}

3.1. Respondents' Demographic Characteristics. Mean age of respondents was $28.5 \pm 10.3$ years and $53.7 \%$ were in the age group $30-40$ years. Some $(35.4 \%)$ of the respondents had at least Secondary Education, Ordinary National Diploma/National Certificate of Education (20.9\%), and $12.6 \%$ had Higher National Diploma/First degree. The majority $(83.1 \%)$ of the respondents were Muslims and $97.4 \%$ were of Yoruba tribe. Almost all (98.4\%) of the respondents were currently married while $1.6 \%$ were cohabiting. The majority (91.1\%) of the respondents had at least a child and $8.1 \%$ had two or more wives.

3.2. Knowledge of Family Planning. The overall mean knowledge score of the respondents was $10.1 \pm 3.1$ and only $57.0 \%$ had a good knowledge of FP. This finding is in contrast with a similar finding in Pakistan [17]. The majority (98.6\%) of the respondents knew that FP is a service for the prevention of pregnancy. This corroborates a previous finding [19]. The majority of the FGDs participants also said FP is a way of preventing a woman from getting pregnant and identified the nurses and doctors as service providers. The majority (90.4\%) knew that unwanted weight gain (90.4\%), vomiting (32.4\%), and abnormal menstruation (42.4\%) were side effects of FP. This finding also corroborates a similar study [20]. All (100.0\%) the respondents identified condom as a FP method. This is in contrast with a previous finding in Ethiopia [21]. Other methods of FP identified by the respondents were pills (90.0\%), IUD (64.2\%), and injectable contraceptives $(81.4 \%)$ (Table 1). The high level of knowledge on at least one form of contraception among the participants of this study is in line with researches done in Ethiopia [10, 21], Yemen [22], 
TABLE 1: Knowledge of FP.

\begin{tabular}{lcc}
\hline Knowledge of FP & Yes $(\%)$ & No (\%) \\
\hline Family planning is a method of & $500(100.0 \%)^{* *}$ & $0(0.0 \%)$ \\
preventing pregnancy & & \\
Methods of FP known & & $50(10.0 \%)$ \\
Pills & $450(90.0 \%)^{* *}$ & $179(35.8 \%)$ \\
IUD & $321(64.2 \%)^{* *}$ & $93(18.6 \%)$ \\
Injectable & $407(81.4 \%)^{* *}$ & $298(59.6 \%)$ \\
Implants & $202(40.4 \%)^{* *}$ & $0(0.0 \%)$ \\
Condom & $500(100.0 \%)^{* *}$ & $490(98.0 \%)$ \\
Female sterilization & $10(2.0 \%)^{* *}$ & \\
Advantages of FP* & $450(90.0 \%)^{* *}$ & $50(10 \%)$ \\
To avoid early and late pregnancy & $480(96.0 \%)^{* *}$ & $20(4.0 \%)$ \\
Limits the number of pregnancy & $320(64.0 \%)^{* *}$ & $180(36.0 \%)$ \\
Prevents abortion & $121(24.2 \%)^{* *}$ & $379(75.8 \%)$ \\
Prevents maternal death & & \\
Side effects of FP & $162(32.4 \%)^{* *}$ & $338(67.6 \%)$ \\
Vomiting & $212(42.4 \%)^{* *}$ & $288(57.6 \%)$ \\
Abnormal menstruation & $452(90.4 \%)^{* *}$ & $48(9.6 \%)$ \\
Unwanted weight gain & & \\
\hline
\end{tabular}

${ }^{*}$ Multiple responses.

${ }^{* *}$ Correct responses.

Pakistan [17], and similar research done in Nigeria [4]. The majority of the FGD participants also reported injectable contraceptives, condom, and the pills as methods of FP. Only few of the participants mentioned IUD and implants while none of the respondents perceived female sterilization as a method of FP. Female sterilization has not been accepted as a popular method of contraception in developing countries like Nigeria [23-25]. However, the percentage of contraceptors who rely on female sterilization is $<0.5 \%$ [26]. This may be due to the reported aversion to operative procedures and the permanent nature of the method [27, 28]. Other methods of FP mentioned among many of the FGD participants are periodic abstinence and withdrawal. A participant in younger group said:

"I know many methods of family planning like pills, condom and periodic abstinence."

Another participant in younger group said:

"IUD and Injectable are some of the methods of family planning that I know and even withdrawal method."

A participant in older group said:

"Pills, IUD, Injectable and condom are some of the methods of FP that I know."

Another participant in older group said:

"Implant is one of the family planning methods but not commonly used among women but IUD and pills are mostly used methods among women."

3.3. Perception of FP. More than half (69.8\%) of the respondents had a positive perception score while $30.2 \%$ had negative perception score. Respondents mean perception score was $4.4 \pm 3$.7. The mean perception scores of respondents in monogamous and polygamous family were $8.2 \pm 3.7$ and $5.7 \pm 2.1$ points, respectively $(P<0.05)$. The perception of $20.8 \%$ was that only women who are promiscuous use FP without their husband's consent and 54.8\% were of the perception that attending FP clinic is entirely the woman's issue and not the man. This corroborates a similar finding from Nigeria [29]. Wadembere [30] also revealed that very few of the respondents discuss FP with their women since most believe that issues related to children and child birth are the responsibility of women. The perception of $48.8 \%$ was that husband should follow his wife to FP clinic only when his attention is needed (Table 2). Many of FGD participants were also of the perception that FP is good but not culturally accepted for a man to be involved in it. A participant in younger group said:

"I cannot just imagine a man getting involved in FP. Am not saying FP is not good but not in our culture for men to participate in it because it is a women's activity."

Another participant said:

"FP is entirely women's affairs and nothing concern we their husbands expect to give them money for it if necessary."

Some FGD participants were of the perception that it is good for men to be involved in FP to show love to the wife and also to have better understanding of the FP. A participant in younger group said:

"It would be better if we get involve in FP so that we can get to increase our understanding of what it entails." 
TABLE 2: Respondents' perceptions of family planning.

\begin{tabular}{|c|c|c|c|}
\hline Statements & Agree & Undecided & Disagree \\
\hline $\begin{array}{l}\text { It is only women who are promiscuous } \\
\text { that use FP without their husband } \\
\text { consent }^{*}\end{array}$ & $104(20.8 \%)$ & $300(60.0 \%)$ & $96(19.2 \%)$ \\
\hline $\begin{array}{l}\text { Attending FP clinic is entirely the } \\
\text { woman's issue and not the man* }\end{array}$ & $274(54.8 \%)$ & $30(6.0 \%)$ & $196(39.2 \%)$ \\
\hline $\begin{array}{l}\text { Attending FP clinic with wife is a waste of } \\
\text { time* }\end{array}$ & $174(34.8 \%)$ & $182(36.4 \%)$ & $144(28.8 \%)$ \\
\hline $\begin{array}{l}\text { FP is important in the area of improving } \\
\text { the health of women }\end{array}$ & $419(83.8 \%)$ & $71(14.2 \%)$ & $10(2.0 \%)$ \\
\hline $\begin{array}{l}\text { Men should assist their women in getting } \\
\text { care from a competent FP provider }\end{array}$ & $391(78.2 \%)$ & $101(20.2 \%)$ & $8(1.6 \%)$ \\
\hline $\begin{array}{l}\text { Husband should follow his wife to FP } \\
\text { only when his attention is needed }\end{array}$ & $244(48.8 \%)$ & $181(36.2 \%)$ & $75(15.0 \%)$ \\
\hline
\end{tabular}

${ }^{*}$ Negative perception.

Another participant said:

"I support male involvement in FP because is a way of showing love to our wives."

Also a participant in older group said:

"I do not see anything wrong in male involvement in FP just that we are too busy."

3.4. Respondents' Spouse Practice of FP. Many (56.5\%) of the respondents generally approved of women's contraceptive use but only $45.8 \%$ of these would allow their own spouse to use contraceptives. This proportion is lower than what was reported in similar findings from Ethiopia [19, 31] and Pakistan [17]. Male partner's approval can be an important predictor of contraceptive use by women [32] and men's acceptance of contraception requires knowledge about appropriate contraceptive methods, more communication between partners, fostering awareness, and mutual sharing of concerns for partners' contraceptive practices [33]. Some (37.9\%) of the respondents reported that their spouses had ever used contraceptives (Figure 1) and out of which 19.0\% were current users (Figure 2). Other studies have already described similar findings, that is, high awareness but low utilization of contraceptives, making this situation a serious challenge in developing countries [34, 35]. Some (17.9\%) of the respondents reported that their spouse was using emergency contraceptive as a primary method of family planning [Figure 3]. This is extremely problematic because emergency contraceptive is only recommended as a backup method for married women [36]. Emergency contraception is needed when intercourse is unexpected and without prior contraceptive coverage. Other indications include failure of barrier methods like the slipping or breakage of condoms and after rape [37]. Most of the FGD participants also reported that their wife had ever used contraceptive and mostly reported that contraceptives were condom and IUD.

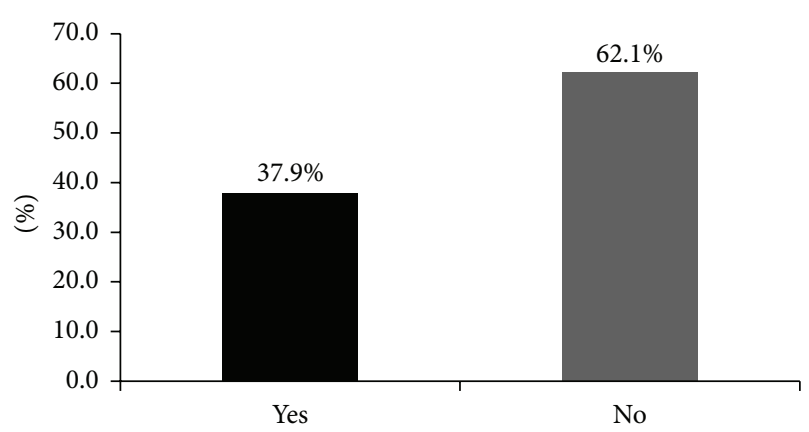

FIGURE 1: Ever used contraceptive by spouse.

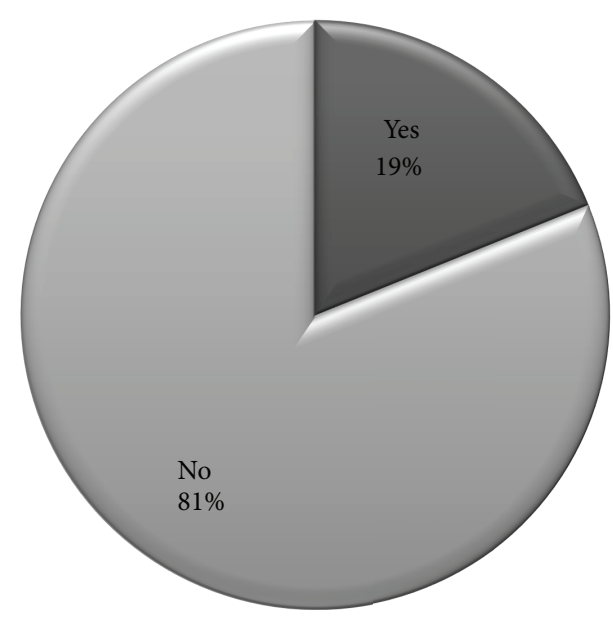

FIGURE 2: Spouse currently using contraceptives.

A participant in younger group said:

"Condom is our family planning method in my family because I have told my wife not to do any other method." 


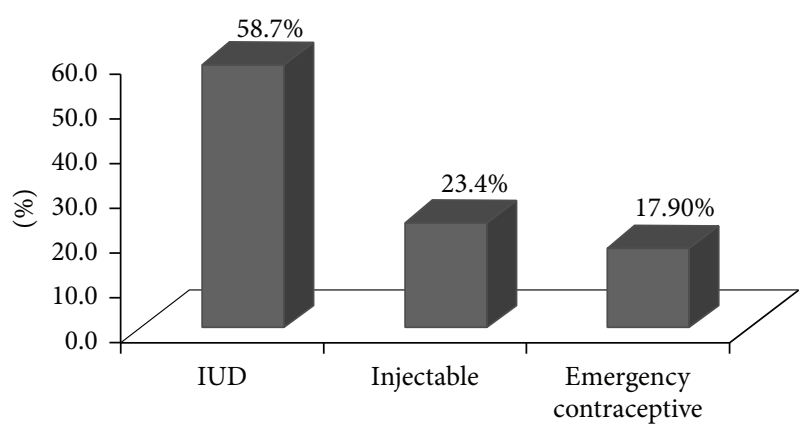

FIGURE 3: FP methods currently used by respondents' spouse.

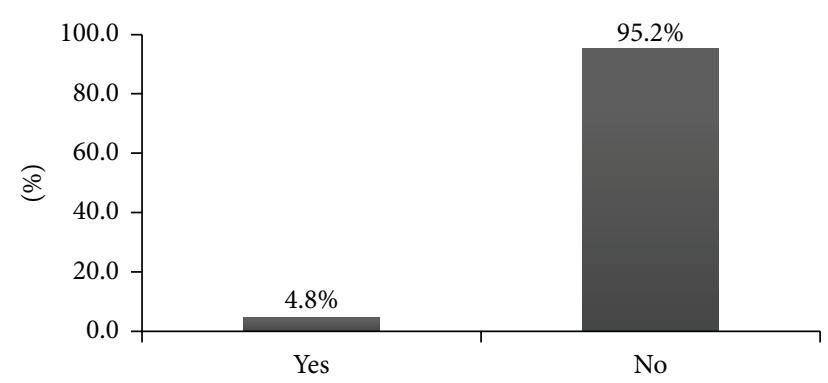

Figure 4: Ever involved in FP with wife.

Another participant in younger group said:

"My wife is also using FP and I think she's using IUD."

A participant in older group said:

"My wife had used family planning in the past but she had to stop it because I did not support her and this was because I know that family planning is dangerous for women."

3.5. Respondents' Involvement in FP. Only $4.8 \%$ of respondents reported to had ever been involved in family planning with their wives (Figure 4). Males are primarily considered as a means of increasing contraceptive prevalence [38]. The multiple decision-making roles of men in reproductive health, particularly family planning, have profound influences on women's health [39]. The reported involvements among these respondents were provision of money for FP (80.9\%), accompanied wife to FP clinic (15.5\%), and discussion about FP with wife $(60.2 \%)$. This is in accordance with a research done in Ethiopia [19] but inconsistent with the result of the study done in Hosanna [40]. Communication about family planning is critical. Interspousal communication is a key issue that affects the sustained use of family planning in Nigeria [41, 42]. Several other studies suggest a strong positive effect of spousal communication on contraceptive use [4349]. Few of the FGD participants also said they had ever accompanied their wife to family planning clinic, ever made financial contribution, and ever discussed family planning with wife. A participant younger group said:

"Have discussed family planning with my wife because have told her I do not want more than three children. Also have accompanied her to family planning clinic before though I stayed inside my car because all the health workers in the clinic were women."

Another participant in younger group also said:

"I think my own involvement is just financial support because my wife is currently using IUD and I paid for it. Though I love to be involved more than this but there is no time for me."

A participant in older group said:

"Though have not really been involved in family planning with my wife but many times she has discussed about various methods with me to know which one she should go for."

3.6. Barriers to Male Involvement in FP. Identified barriers to male involvement were the perception that FP is woman's activity (89.4\%) and were not their custom to participate in FP programme (90.6\%). This is similar to the findings in Uganda [50]. Other barriers reported by respondents were long waiting times at FP clinic (80.9\%), FP not male-friendly (90.1\%), attitude of health workers (70.3\%), and finance (69.4\%). This is similar to the findings in Cameroon [51]. FGD participants also reported societal norms, lack of finance, inadequate time, and FP service not being male-friendly as barriers to their involvement in FP. A participant in older group said:

"I think the major problem we have with our involvement in family planning is that it is a women's activity."

Another participant also in younger group said:

"I cannot imagine following my wife to family planning clinic because even at the clinic you cannot see male health workers who are family planning providers. Then what would I go and do there."

A participant in older group said:

"Negative attitude of health workers is what I see as a major barrier because have followed my wife to antenatal service during her first pregnancy and my experience there was totally bad with the way the health workers were treating the pregnant women. I was not happy at all and most men cannot tolerate that kind of attitude toward them."

Another participant in older group said:

"Men's participation in family planning is not in our culture and we must respect our culture. As the head of this community, I cannot support them." 
3.7. Facilitating Factors for Male Involvement in FP. Listed factors that could facilitate men's involvement in FP were motivation from their wife $(87.6 \%)$, government policy regarding men's role in FP (30.7\%), more FP clinic $(65.2 \%)$, and adequate sensitization for men (85.2\%). Various studies have shown that providing men with information and involving them in counseling sessions can help them to be more supportive of contraceptive use and more aware of the concept of shared decision making [52]. Other facilitating factors were attitudinal change of health workers $(78.7 \%)$ and involvement of male religious leaders as FP advocates (30.4\%). FGD participants also suggested that government should provide more FP clinic to ease access and also make the service free for women. A participant in younger group specifically said:

"Government should provide more FP clinic to make access to health facilities easy."

Another participant in younger group said:

"Government should provide more health centres especially for people in rural areas."

Another suggestion was attitudinal change of health care providers especially the nurses. A participant in older group said:

"Necessary authority should try and improve the attitude of the medical personnel especially the nurses because majority of them do not have good human relation and that is the major reason why I hate going to health centre."

Another participant in older group said:

\begin{abstract}
"The way we can encourage men to follow their wives to FP clinic is if government can educate their health personnel to change their attitude better towards their clients."
\end{abstract}

\section{Conclusion}

The majority of the respondents had never been involved themselves in FP with their wife and this may be attributed to negative perceptions recorded among them. The cultural barrier in itself without any other external influence will demotivate men from getting involved in FP programme. Community sensitization programmes aimed at improving male involvement in FP should be provided by government and nongovernmental agencies. In addition there is need to engage community and opinion leaders so that they can advocate for the use of FP methods in their community. Various studies have shown that providing men with information and involving them in counseling sessions can help them to be more supportive of contraceptive use and more aware of the concept of shared decision making.

\section{Conflict of Interests}

The authors declare no conflict of interests.

\section{Acknowledgments}

The authors' appreciation goes to Health Promotion Specialist at the Faculty of Public Health, University of Ibadan, Nigeria, for providing professional inputs during this study data collection. They must also extend their acknowledgment to the participants at the 2013 International Conference on Family Planning who provided professional input when this paper was presented. The authors sincerely appreciate the immense support and cooperation received from the study participants, supervisors, and the data collectors. They also acknowledge the review of this paper by Olaleye Oladipupo, Fakunle Gregory, and Hassan Seyi Mojisola.

\section{References}

[1] National Population Commission (NPC) [Nigeria] and ICF Macro, Nigeria Demographic and Health Survey 2008, National Population Commission and ICF Macro, Abuja, Nigeria, 2009.

[2] A. Ankomah, J. Anyanti, S. Adebayo, and A. Giwa, "Barriers to contraceptive use among married young adults in Nigeria: a qualitative study," International Journal of Tropical Disease \& Health, vol. 3, no. 3, pp. 267-282, 2013.

[3] C. Nzioka, Programming for Male Involvement in Reproductive Health. Report of the Meeting of WHO Regional Advisors in Reproductive Health, WHO/PAHO, World Health Organization, Geneva, Switzerland, 2002.

[4] K. Oyediran and U. Isiugo-Abanihe, "Husband-wife communication and couple's fertility desires among the Yoruba of Nigeria," African Population Studies, vol. 17, pp. 61-80, 2002.

[5] V. A. Paz Soldan, "How family planning ideas are spread within social groups in rural Malawi," Studies in Family Planning, vol. 35, no. 4, pp. 275-290, 2004.

[6] A. E. Biddlecom and B. M. Fapohunda, "Covert contraceptive use: prevalence, motivations, and consequences," Studies in Family Planning, vol. 29, no. 4, pp. 360-372, 1998.

[7] E. Okwor and I. Olaseha, "Married men's perception about spousal use of modern contraceptives: a qualitative study in Ibadan northwest local government area, southwest Nigeria," International Quarterly of Community Health Education, vol. 30, no. 3, pp. 223-238, 2010.

[8] T. Wambui, A. C. Ek, and S. Alehagen, "Perceptions of family planning among low-income men in Western Kenya," International Nursing Review, vol. 56, no. 3, pp. 340-345, 2009.

[9] K. A. Obisesan, A. A. Adeyemo, and B. O. Fakokunde, "Awareness and use of family planning methods among married women in Ibadan, Nigeria," East African Medical Journal, vol. 75, no. 3, pp. 135-138, 1998.

[10] F. E. Okonofua, C. Odimegwu, H. Ajabor, P. H. Daru, and A. Johnson, "Assessing the prevalence and determinants of unwanted pregnancy and induced abortion in Nigeria," Studies in Family Planning, vol. 30, no. 1, pp. 67-77, 1999.

[11] V. O. Otoide, F. Oronsaye, and F. E. Okonofua, "Why Nigerian adolescents seek abortion rather than contraception: evidence from focus-group discussions," International Family Planning Perspectives, vol. 27, no. 2, pp. 77-81, 2001.

[12] A. Ankomah, M. Oladosu, and J. Anyanti, "Myths, misinformation and communication about family planning and contraceptive use in Nigeria," Open Access Journal of Contraception, vol. 2, pp. 95-105, 2011. 
[13] E. O. Orji and U. Onwudiegwu, "Prevalence and determinants of contraceptive practice in a defined Nigerian population," Journal of Obstetrics and Gynaecology, vol. 22, no. 5, pp. 540543, 2002.

[14] N. Diamond-Smith, M. Campbell, and S. Madan, "Misinformation and fear of side-effects of family planning," Culture, Health and Sexuality, vol. 14, no. 4, pp. 421-433, 2012.

[15] D. Shattuck, B. Kerner, K. Gilles, M. Hartmann, T. Ngombe, and G. Guest, "Encouraging contraceptive uptake by motivating men to communicate about family planning: the Malawi Male Motivator project," The American Journal of Public Health, vol. 101, no. 6, pp. 1089-1095, 2011.

[16] M. Hartmann, K. Gilles, D. Shattuck, B. Kerner, and G. Guest, "Changes in couples' communication as a result of a maleinvolvement family planning intervention," Journal of Health Communication, vol. 17, no. 7, pp. 802-819, 2012.

[17] H. Hussain, I. Wahid, A. A. Khan, Z. U. Rehman, B. Iftikhar, and T. Ismail, "The role of effective communication between couples about contraceptive use," Journal of Medical Sciences, vol. 20, no. 1, pp. 19-21, 2012.

[18] O. Olayemi, C. O. Aimakhu, F. A. Bello et al., "The influence of social support on the duration of breast-feeding among antenatal patients in Ibadan," Journal of Obstetrics and Gynaecology, vol. 27, no. 8, pp. 802-805, 2007.

[19] A. Berhane, S. Biadgilign, A. Amberbir, S. Morankar, A. Berhane, and K. Deribe, "Men's knowledge and spousal communication about modern family planning methods in Ethiopia," African Journal of Reproductive Health, vol. 15, no. 4, pp. 24-32, 2011.

[20] O. O. Odu, K. T. Ijadunola, J. O. Komolafe, and W. T. Adebimpe, "Men's knowledge of and attitude with respect to family planning in a suburban Nigerian community," Nigerian Journal of Medicine, vol. 15, no. 3, pp. 260-265, 2006.

[21] S. Ismail, "Men's knowledge, attitude and practices of family planning in North Gondar," Ethiopian Medical Journal, vol. 36, no. 4, pp. 261-271, 1998.

[22] C. W. Warren, F. Hiyari, P. A. Wingo, A. M. Abdel-Aziz, and L. Morris, "Fertility and family planning in Jordan: results from the 1985 Jordan Husbands' Fertility Survey," Studies in Family Planning, vol. 21, no. 1, pp. 33-39, 1990.

[23] A. G. Adesiyun, "Female sterilization by tubal ligation: a reappraisal of factors influencing decision making in a tropical setting," Archives of Gynecology and Obstetrics, vol. 275, no. 4, pp. 241-244, 2007.

[24] EngenderHealth, Contraceptive Sterilisation: Global Issues and Trends, Automated Graphic Systems Inc., White Plains, Md, USA, 1st edition, 2002.

[25] O. O. Adetoro, "The pattern of eclampsia at the University of Ilorin Teaching Hospital (U.I.T.H.) Ilorin, Nigeria," International Journal of Gynecology and Obstetrics, vol. 31, no. 3, pp. 221-226, 1990.

[26] A. O. Aisien and A. U. Oronsaye, "Two decades of minilaparotomy female sterilization at the University of Benin Teaching Hospital," The Nigerian Postgraduate Medical Journal, vol. 14, pp. 67-71, 2007.

[27] S. O. Ogunniyi, B. L. Faleyimu, and O. Ifaturoti, "Female surgical contraception in Ile-Ife: an eight year review," The Nigerian Medical Practitioner, vol. 21, pp. 72-74, 1991.

[28] T. Z. Swende, E. T. Agida, and A. A. Jogo, "Elective caesarean section at the Federal Medical Centre Makurdi, north central Nigeria," Nigerian Journal of Medicine, vol. 16, no. 4, pp. 372374, 2007.
[29] T. O. Lawoyin, H. Osinowo, M. Babatunde et al., "Family planning in rural Nigeria: a study among men," African Journal of Medicine and Medical Sciences, vol. 31, no. 2, pp. 159-162, 2002.

[30] W. I. Jangu, Attitude and Willingness of Men towards the Use of Modern Family Planning Methods in Budondo Sub-County, Makerere University, School of Public Health, Jinja, Uganda, 2013.

[31] T. Tilahun, G. Coene, S. Luchters et al., "Family planning knowledge, attitude and practice among married couples in Jimma Zone, Ethiopia," PLoS ONE, vol. 8, no. 4, Article ID e61335, 2013.

[32] M. R. Joesoef, A. L. Baughman, and B. Utomo, "Husband's approval of contraceptive use in metropolitan Indonesia: program implications," Studies in Family Planning, vol. 19, no. 3, pp. 162-168, 1988.

[33] C. P. Green, "Male involvement in reproductive health and family planning," Programme Advisory Note, Technical Paper, United Nations Population Fund, New York, NY, USA, 1994.

[34] S. Becker, "Measuring unmet need: wives, husbands or couples?” International Family Planning Perspectives, vol. 25, no. 4, pp. 172-180, 1999.

[35] L. O. Omo-Aghoja, V. W. Omo-Aghoja, F. E. Okonofua et al., "Perceptions and attitudes of a rural community to abortion in the Niger-delta region of Nigeria," Nigerian Journal of Clinical Practice, vol. 12, no. 4, pp. 443-449, 2009.

[36] Family Health International, "Emergency contraception as a backup method," Network, vol. 17, no. 2, pp. 12-13, 1997.

[37] A. A. Haspels, "Emergency contraception: a review," Contraception, vol. 50, no. 2, pp. 101-108, 1994.

[38] M. R. Dudgeon and M. C. Inhorn, "Men's influences on women's reproductive health: medical anthropological perspectives," Social Science and Medicine, vol. 59, no. 7, pp. 1379-1395, 2004.

[39] N. J. Piet-Pelon, U. Rob, and M. E. Khan, Men in Bangladesh, India and Pakistan: Reproductive Health Issues, Karshaf Publishers, Dhaka, Bangladesh, 2000.

[40] T. Tsedeke, D. Wakgari, A. Ahmed, and D. Gali, “The role of men in contraceptive use and fertility preference in Hosanna Town, Southern Ethiopia," Ethiopian Journal of Health Development, vol. 20, no. 3, pp. 135-205, 2006.

[41] B. J. Feyisetan, "Spousal communication and contraceptive use among the Yoruba of Nigeria," Population Research and Policy Review, vol. 19, no. 1, pp. 29-45, 2000.

[42] P. O. Ogunjuyigbe, E. O. Ojofeitimi, and A. Liasu, "Spousal communication, changes in partner attitude, and contraceptive use among the Yorubas of Southwest Nigeria," Indian Journal of Community Medicine, vol. 34, no. 2, pp. 112-116, 2009.

[43] A. A. Bawah, "Spousal communication and family planning behavior in Navrongo: a longitudinal assessment," Studies in Family Planning, vol. 33, no. 2, pp. 185-194, 2002.

[44] M. Oladosu, Couples' decision making and reproductive outcomes in Uganda [Ph.D. thesis], Pennsylvania State University, Philadelphia, Pa, USA, 1999.

[45] K. R. Katz, C. G. West, F. Doumbia, and F. Kané, "Increasing access to family planning services in rural mali through community-based distribution," International Family Planning Perspectives, vol. 24, no. 3, pp. 104-110, 1998.

[46] Y. Oheneba-Sakyi and K. B. Takyi, "Effects of couples' characteristics on contraceptive use in sub-Saharan Africa: the Ghanaian example," Journal of Biosocial Science, vol. 29, pp. 33-49, 1997. 
[47] O. E. Tawiah, "Factors affecting contraceptive use in Ghana," Journal of Biosocial Science, no. 29, pp. 141-149, 1997.

[48] W. K. A. Agyei and M. Migadde, "Demographic and sociocultural factors influencing contraceptive use in Uganda," Journal of Biosocial Science, vol. 27, no. 1, pp. 47-60, 1995.

[49] E. O. Orji, C. A. Adegbenro, B. I. Akinniranye, G. O. Ogunbayo, and A. E. Oyebadejo, "Spousal communication on family planning as a safe motherhood option in Sub-Saharan African communities," Journal of Chinese Clinical Medicine, vol. 2, no. 6, pp. 328-335, 2007.

[50] A. Kabagenyi, L. Jennings, A. Reid, G. Nalwadda, J. Ntozi, and L. Atuyambe, "Barriers to male involvement in contraceptive uptake and reproductive health services: a qualitative study of men and women's perceptions in two rural districts in Uganda," Reproductive Health, vol. 11, article 21, 2014.

[51] G. N. Nkuoh, D. J. Meyer, P. M. Tih, and J. Nkfusai, "Barriers to men's participation in antenatal and prevention of motherto-child HIV transmission care in Cameroon, Africa," Journal of Midwifery and Women's Health, vol. 55, no. 4, pp. 363-369, 2010.

[52] E. Wells, "Involving men in reproductive health," Outlook, vol. 14, no. 3, pp. 1-8, 1997. 

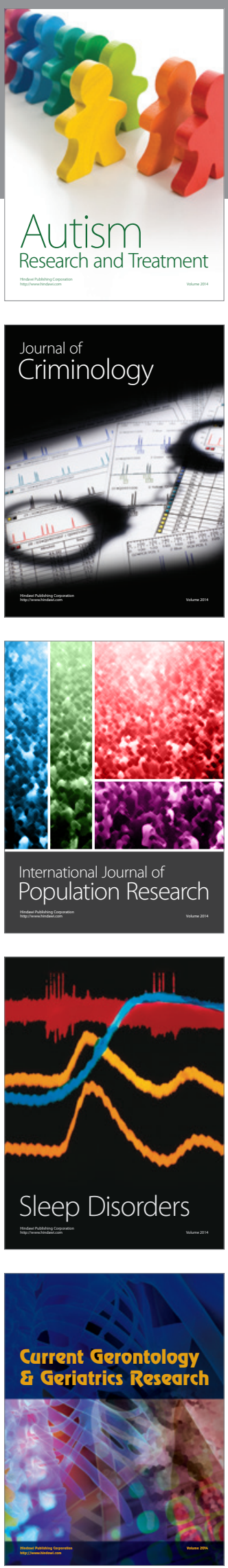
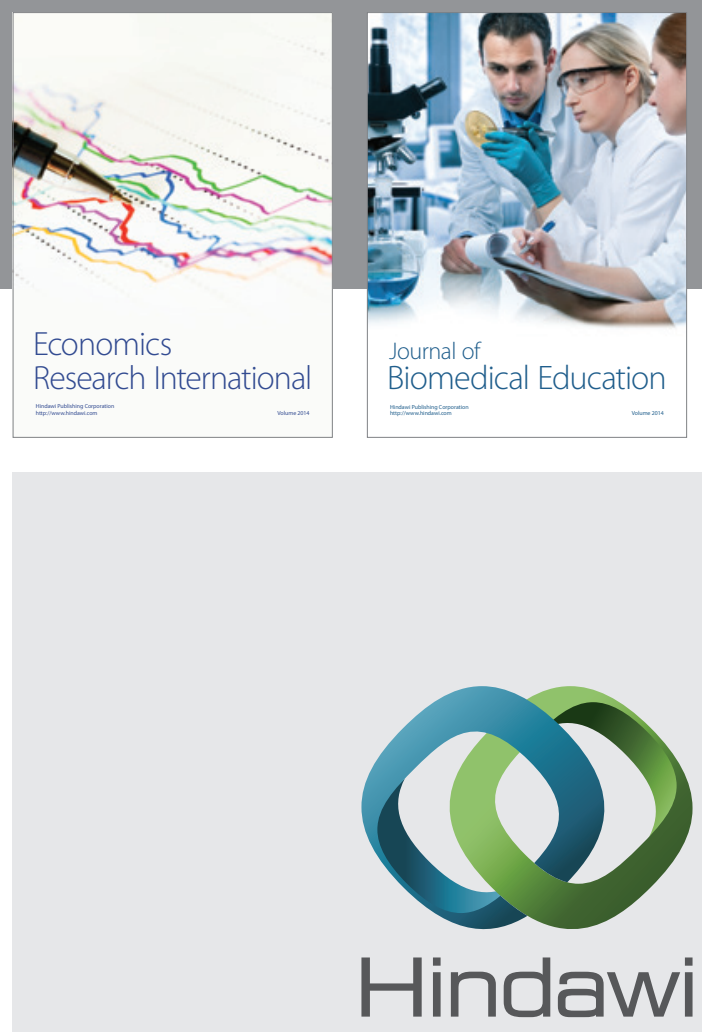

Submit your manuscripts at

http://www.hindawi.com
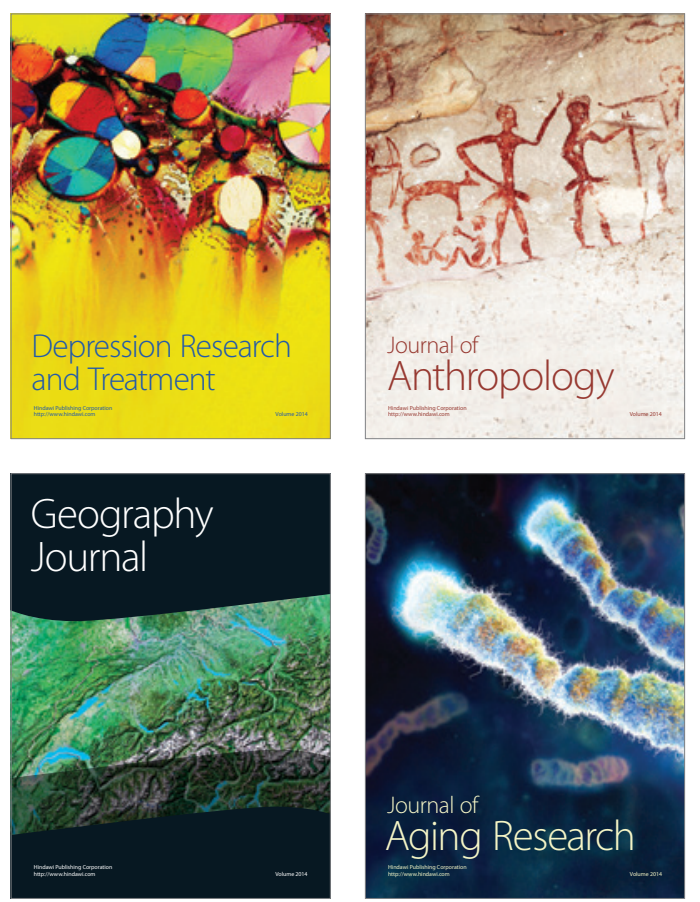
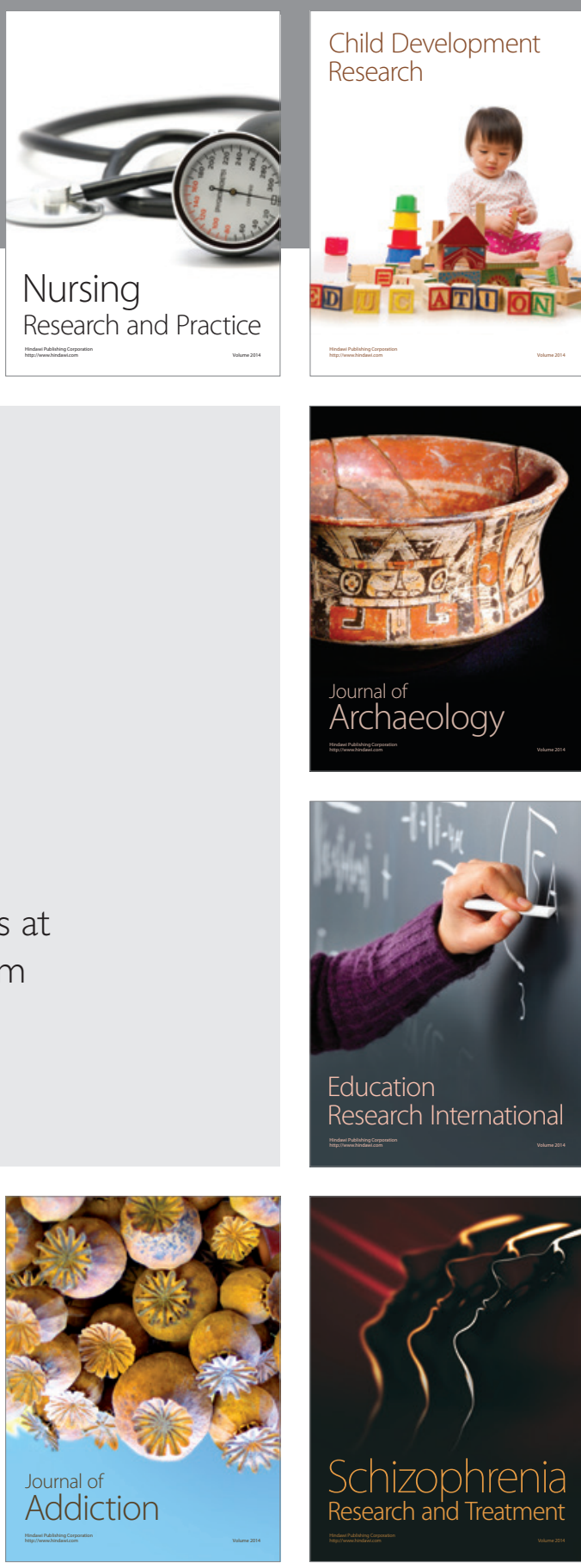

(D)
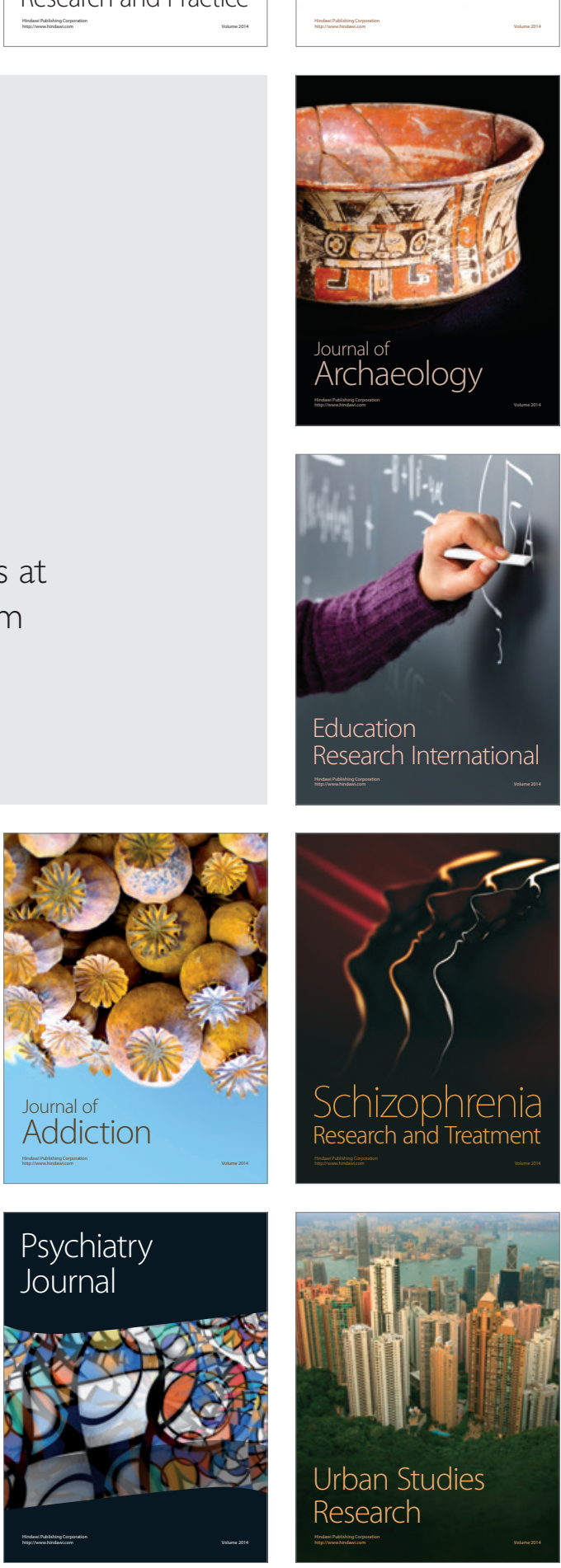